\title{
Percurso investigativo de um curso de capacitação para professores com o uso de recurso tecnológico na alfabetização de alunos com Transtorno do Espectro Autista
}

Investigative route of a teacher training course using technological resource in the literacy of students with Autistic Spectrum Disorder

Ruta de investigación de un curso de formación docente que utiliza recursos tecnológicos en la alfabetización de estudiantes con Trastorno del Espectro Autista

\section{Danieli Ferreira Guedes}

Mestra pela Universidade Estadual do Norte do Paraná, Cornélio Procópio, Paraná, Brasil. danieliguedescp@gmail.com

ORCID - https://orcid.org/0000-0002-8218-8179

\section{João Coelho Neto}

Professor doutor na Universidade Estadual do Norte do Paraná, Cornélio Procópio, Paraná, Brasil. joaocoelho@uenp.edu.br

ORCID - https://orcid.org/0000-0002-6154-3266

\section{Marília Bazan Blanco}

Professora doutora na Universidade Estadual do Norte do Paraná, Cornélio Procópio, Paraná, Brasil. mariliabazan@uenp.edu.br

ORCID - https://orcid.org/0000-0001-9259-0578

Recebido em 15 de janeiro 2020

Aprovado em 15 de agosto de 2020

Publicado em 30 de setembro de 2020

\section{RESUMO}

As tecnologias digitais educacionais podem contribuir no contexto escolar, principalmente para a Educação Especial, possibilitando a inclusão de alunos com necessidades educacionais especiais, inclusive auxiliando os alunos com Transtorno do Espectro Autista, visto ser um transtorno do desenvolvimento que tem início na infância e que se caracteriza por atrasos significativos na aquisição de linguagem, interação social e comportamentos repetitivos e estereotipados. Essas contribuições podem ser muitas, pois visam desenvolver a habilidade social, a linguagem e a aprendizagem de conteúdos escolares, assim, produzindo conhecimento, explorando e executando ações por meio de recurso tecnológico. Desse modo, essa pesquisa tem como objetivo geral desenvolver um curso de capacitação para docentes que atuam com alunos com Transtorno do Espectro Autista, com finalidade do uso de recursos tecnológicos para a alfabetização de alunos com esse transtorno. O encaminhamento metodológico utilizado contemplou as seguintes etapas: fundamentação teórica estruturada em uma revisão bibliográfica com base em pesquisas e na abordagem qualitativa para a elaboração do produto educacional, que objetivou produzir um curso de capacitação para docentes. $O$ trato com os dados ocorreu a partir dos pressupostos da Análise Textual Discursiva, com a utilização de entrevistas, diário de bordo 
http://dx.doi.org/10.5902/1984686X41874

e questionário final. Portanto, a contribuição desse curso foi relevante no sentido de promover reflexões entre seus participantes acerca da importância da formação pedagógica continuada para o conhecimento sobre o Transtorno do Espectro Autista e sobre a alfabetização desses alunos por meio do recurso tecnológico.

Palavras-chave: Tecnologias digitais; Transtorno do Espectro Autista; alfabetização; curso de extensão.

\section{ABSTRACT}

Digital educational technologies can contribute in the school context, mainly for Special Education, enabling the inclusion of students with special educational needs, essentially helping students with Autism Spectrum Disorder, since it is a developmental disorder that begins in childhood and it is characterized for significant delays in language acquisition, social interaction, and repetitive and stereotyped behaviors. These contributions may be various, since they aim to develop social skills, the language and school contents learning, this way producing knowledge, exploring and executing actions through the technological resource. Thus, this research has as general objective to develop a training course for teachers that work with students with Autism Spectrum Disorder, in the city North of Paraná, with the purpose of using technological resources for the literacy of students with Disorder Spectrum of Autism. The methodological approach used included the following steps: theoretical foundation structured in bibliographical review based on research and the qualitative approach to the elaboration of the educational, product which aimed produce a training course for teachers. The deal with the data occurred from the assumptions of the Discursive Textual Analysis, by using interviews, diaries and a final questionnaire. Therefore, the contribution of this course was relevant in order to promote reflections among its participants about the importance of continuing pedagogical formation for the knowledge about Autistic Spectrum Disorder and about the literacy of these students through the techonological resource.

Keywords: Digital technologies; Autism Spectrum Disorder; literacy; extension course.

\section{RESUMEN}

Las tecnologias digitales educativas pueden contribuir en el contexto escolar, especialmente a la educación especial, permitiendo la inclusión de estudiantes con necesidades educativas especiales, incluida la asistencia a estudiantes con trastorno del espectro autista, ya que es un trastorno del desarrollo que comienza em la infancia y se caracteriza por retrasos significativos en la adquisición del lengraje, la intercción social y los comportamientos repetitivos y estereotipados. Estas contribuciones pueden ser muchas, ya que su objetivo es desarrollar la capacidad social, el linguaje y el aprendizaje de los contenidos escolares, produciendo así conocimiento, explorando y ejecutando acciones a través de recursos tecnológicos. Por lo tanto, esta investigación tiene como objetivo desarrollar un curso de capcitación para maestros que trabajan con estudiantes con trastorno del espectro autista, con el propósito de utilizar recursos tecnológicos para la alfabetización de los estudiantes con este trastorno. El enfoque metodológico utilizado incluyó los siguientes pasos: fundamentación teórica estructurada em uma revisión bibliográfica basada em la investigación y el enfoque cualitativo para la elaboración del producto educativo, que tuvo como objetivo realización de um curso de capacitación para docentes. El tratamiento con los datos se produjo a partir de los supuestos del análisis textual discursivo, utilizando entrevistas, caderno de bitácora y cuestionario final. Por lo tanto, la contribución de este curso fue relevante para promover reflexiones entre sus participantes sobre la importancia de continuar la formación pedagógica para el 
conocimiento sobre el trastorno del Espectro Autista y sobre la alfabetización de estos estudiantes a través del recurso tecnológico. Palabras clave: Tecnologías digitales; Transtorno del Espectro Autista; Alfabetización; Curso de extensión.

Palabras clave: Tecnologías digitales; Transtorno del Espectro Autista; alfabetización; curso de extensión.

\section{Introdução}

A inserção de alunos com necessidades educacionais em sala regular vem crescendo no Brasil. Evidencia-se que alguns professores em Educação Especial da Rede Regular de ensino, Classe Especial, ou até mesmo em Sala de Recurso apresentam dificuldades em ensinar alunos com deficiência, transtorno, dificuldades ou síndromes. Segundo Rodrigues, Lima e Vianna (2017), a formação inicial do professor não contempla todos os saberes necessários em face de todas as necessidades de uma sala de aula. Desse modo, é primordial que o profissional continue estudando e realizando, assim, a formação continuada, buscando aprimorar os seus conhecimentos e as suas práticas.

Assim, a teoria fornece uma noção daquilo que, provavelmente, encontra-se na realidade escolar, mas, na prática, no cotidiano de uma sala de aula, fazem-se indispensáveis metodologias diferenciadas, materiais pedagógicos distintos e ações pedagógicas com auxílio de outros recursos como o tecnológico, de acordo com as necessidades dos alunos com deficiência, transtornos globais do desenvolvimento ${ }^{1} \mathrm{e}$ altas habilidade/superdotação.

Guedes (2018) apresenta uma revisão sobre Autismo e Tecnologia, o qual identificando que os trabalhos voltados para essa área abordam a importância do uso dos recursos tecnológicos para o trabalho com alunos autistas, visando o desenvolvimento da linguagem, habilidades sociais e interação pais e filhos. No entanto, na revisão sistemática, não foi identificado nenhum trabalho com propostas de ensino de conteúdos acadêmicos, como a alfabetização utilizando recursos tecnológicos.

Pensando sobre a dimensão de conhecimento a ser buscado em relação ao Transtorno do Espectro Autista e os Recursos Tecnológicos, o objetivo geral da presente pesquisa consiste em desenvolver um curso de capacitação para docentes que atuam na Educação Especial e/ou Escola Regular de Ensino, em uma cidade do norte do Estado do Paraná, para o uso de recursos tecnológicos na alfabetização de alunos com Transtorno do Espectro Autista e, assim, auxiliando na própria construção de materiais midiáticos gratuitos para sua utilização, principalmente, nas escolas pública brasileiras. 
http://dx.doi.org/10.5902/1984686X41874

Dessa forma, o curso de capacitação para docentes visou contribuir para a ação docente efetiva, promovendo momentos de reflexão e aprendizagem sobre definições e características do aluno com Transtorno do Espectro Autista (TEA), bem como sobre métodos e recursos tecnológicos e manipuláveis para alfabetização dos alunos com TEA.

Este artigo foi dividido em cinco seções: a primeira contextualiza a temática e evidencia o objetivo geral do trabalho; a segunda seção apresenta a abordagem teórica sobre o Transtorno do Espectro Autista e o uso das Tecnologias Digitais; a terceira seção discute os encaminhamentos metodológicos; a quarta seção expõe as análises e interpretação dos dados; a quinta e última seção traz as considerações finais.

\title{
Transtorno do Espectro Autista
}

Segundo o DSM-V, indivíduos com Transtorno do Espectro Autista (TEA) apresentam prejuízo na interação social, nas habilidades de comunicação e comportamentos estereotipados (AMERICAN PSYCHIATRIC ASSOCIATION, 2014).

Assim, de acordo com a Associação Psicológica Americana,

\begin{abstract}
transtorno do Espectro Autista também é definido por padrões restritos e repetitivos de comportamento, interesses ou atividades que mostram uma gama de manifestações de acordo com a idade e a capacidade, intervenções e apoios atuais. [...] Adesão excessiva a rotinas e padrões restritos de comportamento podem ser manifestados por resistência às mudanças (por exemplo, sofrimento relativo a mudanças aparentemente pequenas, como embalagem de um alimento favorito; insistência em aderir a regras; rigidez de pensamento) ou por padrões ritualizados de comportamento verbal ou não verbal (p. ex., perguntas repetitivas, percorrer um perímetro). (AMERICAN PSYCHIATRIC ASSOCIATION, 2014, p. 100).
\end{abstract}

Para Bordini e Bruni (2014), o indivíduo com TEA apresenta um prejuízo na sociabilidade, pois exibe pouca interação com pessoas da mesma idade, geralmente evita participar de atividades em dupla ou grupo, também não demonstra iniciativa no contato com os demais. Quanto aos comportamentos restritos e estereotipados, estes são caracterizados por movimentos repetitivos sem finalidade, como, por exemplo, balançar para a frente e para trás. Do mesmo modo, podem apresentar obsessão por assuntos específicos, como personagens de desenho animados, astronomia, entre outros, e apegam-se a rotinas e apresentam dificuldades em lidar com mudanças. No que se refere à comunicação, existem crianças que podem tanto atrasar a fala como também nunca adquirir a linguagem verbal, falar de modo pausado, ou falar de si mesmos na terceira pessoa. 
De acordo com Kovatli (2003, p. 25), "indivíduos autistas apresentam sintomas importantes, os quais podem ser do leve ao severo, dependendo de indivíduo para indivíduo". Assim, as características podem envolver dificuldade de relacionamento com outras crianças, riso inapropriado, pouco ou nenhum contato visual, rotação de objetos, inapropriada fixação em objetos (apalpá-los insistentemente, mordê-los...) e ausência de resposta aos métodos normais de ensino, Gadia (2016, p. 440) apresenta a dificuldade na interação social, comunicação e padrões repetitivos, sendo

\begin{abstract}
comportamento social impróprio, pobre de contato visual, dificuldade em participar de atividades em grupo, indiferença afetiva ou demonstrações inapropriadas de afeto e falta de empatia emocional. A comunicação pode apresentar diferentes graus de dificuldades, tanto na habilidade verbal quanto na não verbal, algumas apresentam uma linguagem imatura, com ecolalia, reversão de pronome e outras apresentam inabilidade em iniciar ou manter uma conversa apropriada. Comportamentos estereotipados, as crianças têm resistência a mudanças, insistência em determinadas rotinas, apego excessivo a objetos específicos e fascínio com o movimento de peças.
\end{abstract}

Contudo, alguns indivíduos autistas também apresentam características com ampla capacidade intelectual, como nas áreas de exatas, e da mesma forma são capazes de aprender a ler por volta dos dois anos. Segundo Kovatli (2003), crianças em contato com computadores desde cedo podem escrever muito antes do tempo adequado para a escrita, embora apresentem uma comunicação restrita.

\title{
As Tecnologias Digitais e a Alfabetização de Alunos com Transtorno do Espectro Autista
}

Os professores, quando recebem em sua sala de aula alunos com necessidades educacionais especializadas, como, por exemplo, aluno com Transtorno do Espectro Autista, necessitam pensar em algumas estratégias de ensino com as quais possam atuar de melhor modo, viabilizando oportunidades de ensino e aprendizagem para que alunos com TEA alcancem sucesso escolar.

Togashi, Moura e Walter (2018) abordam que para os profissionais da educação

faz-se necessário buscar pelas melhores práticas, ou seja, em práticas baseadas em evidências e que já foram cientificamente comprovadas, uma vez que o conhecimento científico empregado no contexto da prática pedagógica favorece um respaldo de resultado mais eficaz e promissor, já comprovado em pesquisas anteriores. 
http://dx.doi.org/10.5902/1984686X41874

A tecnologia digital vem crescendo em todas as áreas, mas, principalmente, na área do Ensino, uma vez que esse recurso pode auxiliar no processo de ensino e de aprendizagem na área da Educação Especial (SEGGER; CANES; GARCIA, 2012).

A intervenção, por meio da tecnologia, para alunos com TEA pode potencializar habilidades e favorecer maior autonomia, obter resultados positivos na fala, auxiliar no controle das alterações de humor, na diminuição das estereotipias e no desenvolvimento da habilidade cognitiva (GOULART; BLANCO; COELHO NETO, 2017).

Além disso, o uso da tecnologia e do computador vem integrado com softwares educacionais, podendo proporcionar aos alunos uma aprendizagem que seja capaz de ser realizada tanto individual quanto coletivamente.

Zanin e Blanco (2009, p. 18) abordam que "os softwares educativos integram diversão e aprendizagem em jogos interativos multidisciplinares, que complementam as experiências dos educandos na escola, trabalham com diferentes habilidades e preferências dos educandos, apresentando as informações de diversas maneiras". Desse modo, o professor, por meio da tecnologia, pode obter uma variedade de opções metodológicas adequadas para ensinar os alunos (MAGALHÃES, 2004).

Sousa (2015) aborda que os professores de sala regular apresentam algumas dificuldades para ensinar alunos autistas, em decorrência de suas dificuldades na socialização e na interação social. A falta de capacitação adequada para trabalhar com esses alunos também é apontada como um agravante nesse contexto.

Para alfabetizar alunos autistas, é necessário que as atividades sejam elaboradas com muita criatividade para adaptar materiais e inserir as letras (SILVA, 2015). Assim, fazse necessário apresentar algumas propostas e estratégias de ensino que possam auxiliar no desenvolvimento desses alunos tanto em sala regular como sala de recurso e classe especial.

\section{Encaminhamento Metodológico}

Para a elaboração desse artigo, utilizou-se recortes teóricos apresentados na dissertação de Omitido (xxxxx), o qual desenvolveu atividades de alfabetização para alunos autistas, com base no método fônico e multissensorial, além de princípios da Análise Comportamental Aplicada, conhecida como ABA.

A pesquisa foi fundamentada nos pressupostos metodológicos da abordagem qualitativa, o qual Flick $(2009$, p. 25) ressalta que 
http://dx.doi.org/10.5902/1984686X41874

os métodos qualitativos consideram a comunicação do pesquisador em campo como parte explícita da produção de conhecimento. Em vez de simplesmente encará-la como uma variável a interferir no processo. A subjetividade do pesquisado, bem como daqueles que estão sendo estudos, tornam-se parte do processo de pesquisa.

Por meio da pesquisa qualitativa, o pesquisador pode aproximar-se das necessidades dos profissionais, especialmente no âmbito educacional.

Desse modo, considera-se que a pesquisa qualitativa possui uma relação ativa entre o mundo existente e o sujeito, significa um vínculo indissociável entre o mundo objetivo e a subjetividade do sujeito, que não pode ser traduzida em números (SILVA; MENEZES, 2005).

O ensino está em constante transformação e, desse modo, a elaboração do curso de capacitação para professores emergiu a partir da necessidade de aprimorar o ensino dos docentes da Educação Especial e Inclusiva, com objetivo de proporcionar aos participantes conhecimentos sobre as causas e características do Transtorno do Espectro Autista (TEA), assim como dos métodos e do uso de recursos manipuláveis e tecnológicos ${ }^{2}$ para sua alfabetização. O curso surgiu a partir das demandas do profissional da educação que busca mais conhecimentos e referenciais teóricos para aperfeiçoar a sua prática em sala de aula, pensando na educação de qualidade e equidade dos alunos.

O curso foi organizado para professores que atuam na Educação Especial e Básica com alunos com TEA em sua prioridade, porém, não se limitando a esse público, caso houvesse interesse de outras áreas. A estrutura e realização do curso foram preparadas conforme a disponibilidade e horários de participantes interessados. Todos os participantes assinaram o Termo de Consentimento Livre e Esclarecido.

Participaram do curso de capacitação 10 professores atuantes tanto da Rede Regular de ensino quanto sala de recurso, atendimento Psicopedagógico Clínico e Institucional na Modalidade Especial e também da área tecnológica, idades entre 25 a 50 anos, com tempo de atuação, na Educação, entre um a vinte e seis anos e, na Educação Especial, entre quatro meses a três anos.

As coletas de dados dos participantes foram realizadas antes, durante e após o curso, assim como as análises. Os dados representam as percepções dos participantes quanto aos métodos de alfabetização do TEA, sobre o recurso tecnológico, elencando suas dificuldades e facilidades, os materiais utilizados, tanto manipuláveis quanto com recursos tecnológicos, bem como sua compreensão e a avaliação do produto educacional, resultando pontos positivos e negativos. 
http://dx.doi.org/10.5902/1984686X41874

Os excertos apresentados das falas dos participantes foram transcritos na íntegra, não sendo realizada a correção gramatical. Os participantes foram codificados pela consoante $\mathrm{P}$ em um número ordinal: P1, P2 ... P10 (indicando o número de participantes).

Com foco no Produto Educacional, a Capacitação para Docentes teve o intuito de instruir os profissionais a trabalharem a alfabetização com alunos autistas, utilizando o recurso tecnológico, especificamente o software LibreOffice $\AA^{3}$. Com a utilização desse recurso é possível criar e desenvolver atividades diferenciadas e específicas, que possam atender a necessidade de cada aluno. Pôde-se realizar atividades com funções do software que chamam a atenção do aluno, contendo botões de acerto e erro, imagens, animações e áudios, com os quais o aluno consegue realizar as atividades de forma independente. Nos encontros ministrados, foram apontadas definições, características e causas sobre o Transtorno do Espectro Autista (TEA) para maior compreensão dos profissionais. Além disso, métodos e programas de trabalho com alunos autistas e propostas de atividades para alfabetização foram abordados, utilizando materiais manipuláveis e o recurso tecnológico. Foram realizadas 10 propostas de atividades de alfabetização, divididas em vogais, sílabas simples e palavras. Para cada atividade, foram apresentados indicações, objetivos, materiais utilizados e descrição da atividade.

O Curso de Capacitação de Professores proposto foi composto por cinco encontros, com carga horária total de 40 horas, distribuídas em 20 horas presenciais e 20 horas de atividades complementares online. As atividades online foram realizadas com questionários, leitura de textos, vídeos e concluído com uma atividade de alfabetização utilizando o recurso tecnológico com software $L i b r e O f f i c e \AA$.

Os resultados obtidos por meio dos instrumentos de coleta de dados, a partir dos pressupostos da Análise Textual Discursiva (ATD), de acordo com Moraes e Galiazzi (2014, p. 7), "corresponde a uma metodologia de análise de dados e informações de natureza qualitativa com a finalidade de produzir novas compreensões sobre os fenômenos e discursos".

No que se refere ao Curso de Capacitação de Professores, na Figura 1, é elencada a categoria com as unidades contribuição na prática em sala de aula, atividades de alfabetização do TEA, aprendizagem do TEA e, por fim, os pontos positivos que o Curso de Capacitação de Professores trouxe para a prática dos profissionais da área da educação Especial e Básica com os alunos com Transtorno do Espectro Autista. 
http://dx.doi.org/10.5902/1984686X41874

Figura 1 - Categoria: Curso de Capacitação

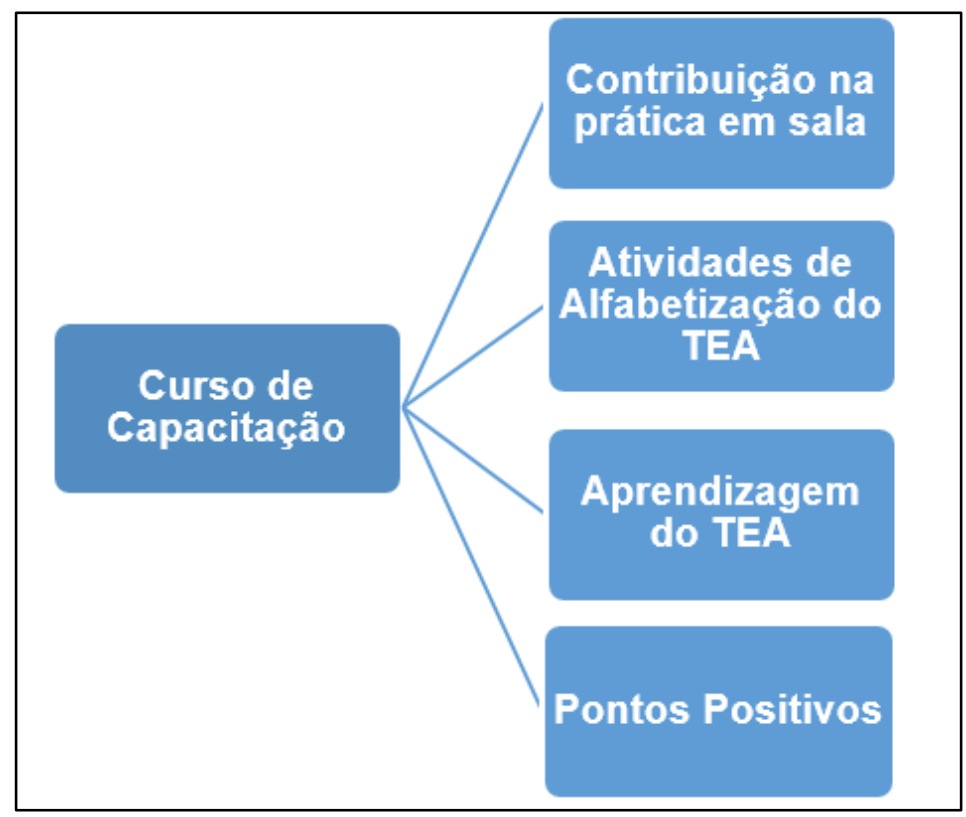

Fonte: Guedes (2018).

\section{Resultados e discussão}

Nessa seção, são apresentadas a proposta do curso de capacitação e a percepção dos participantes, no que tange à sua participação e á construção dos materiais midiáticos para seu uso em sala de aula, objetivando sua utilização para as escolas públicas brasileiras.

\section{Proposta do curso de capacitação}

No primeiro dia de encontro presencial, foi realizada a apresentação dos participantes por meio de uma dinâmica. Esse encontro foi de caráter teórico, com objetivo de instruir sobre os conceitos relacionados ao autismo e aos métodos utilizados para alfabetização com alunos com Transtorno do Espectro Autista. Além disso, esse momento contemplou os Recursos Tecnológicos, expostos de forma oral (exposição dialogada), acompanhados de textos com embasamento teórico e vídeos, dando abertura aos participantes para exporem suas dificuldades e/ou sugestões em relação ao ensino e à aprendizagem desses alunos.

O segundo encontro presencial foi de caráter teórico, com objetivo de abordar sobre a utilização de recursos tecnológicos para alunos autistas, como por exemplo: tablet, 
http://dx.doi.org/10.5902/1984686X41874

notebook, computador, celular e Internet. Do mesmo modo, apresentaram-se alguns softwares como o Lele Sílabas ${ }^{4}$, Aprendendo com a Rotina ${ }^{5}$, ABC Autismo6 ${ }^{6}$, que são utilizados em aplicativo móvel e automatizam o processo de elaboração de atividades educacionais.

Do mesmo modo, foi trabalhado com os professores o método Programa de Treatment and Education of Autistic and related Communication-handicapped Children (TEACCH), que é considerado importante para indivíduos com TEA, no qual, é baseado na adaptação do ambiente, como também no desenvolvimento da independência do aluno (FERREIRA, 2016).

As interfaces autoexplicativas, $\mathrm{SCALA}^{7}$ para Comunicação Alternativa e 0 LibreOffice $\AA$ Impress, foram expostas de forma oral (exposição dialogada), utilizando textos como embasamento teórico e vídeos, esse momento favoreceu aos participantes exporem suas dificuldades e/ou sugestões em relação a utilização tais recursos tecnológicos para 0 ensino e aprendizagem de alunos com TEA.

No terceiro encontro, foram apresentadas as atividades elaboradas sobre alfabetização, bem como as adaptações realizadas para o ensino de alunos com TEA, utilizando materiais como: papel, caneta hidrocor, tesoura, cola, papelão, papel contact, Figuras e/ou imagens, com objetivo de orientar o uso de materiais manipuláveis para integrar atividades para esses alunos.

As imagens utilizadas nas atividades foram pesquisadas no domínio público: https://br.freepik.com/fotos-vetores-gratis/dominio-publico e inseridas no software LibreOffice $\mathbb{B}$ Impress para a impressão. A escolha do tamanho foi feita de acordo com a necessidade do uso, do mesmo modo, podem ser utilizadas figuras de livros didáticos. As atividades para esse encontro foram realizadas com vogais, sílabas e palavras. Entretanto, por meio de apresentação de slide, foram expostas as outras propostas de atividades de alfabetização para alunos autistas, com as explicações necessárias para que esses alunos pudessem realizá-las. Nesse encontro, foram utilizadas orientações propostas do Programa TEACCH, que contribuíram para adaptar atividades didáticas.

O quarto encontro foi de caráter prático com o uso de Recurso Tecnológico com o

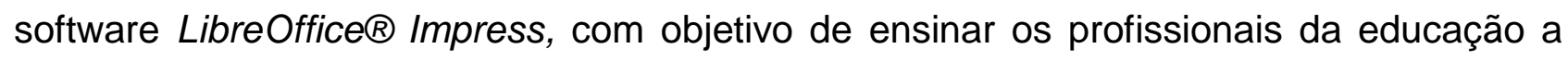
manusear o recurso tecnológico para a elaboração de atividade no software LibreOffice® Impress. Foram apresentadas propostas de atividades para os alunos com TEA mais 
http://dx.doi.org/10.5902/1984686X41874

completas, expostas por meio dos slides, com as explicações passo a passo, de como poderiam ser desenvolvidas, sendo possível utilizar mais ações no software.

Os participantes aprenderam passo a passo como manusear as ações do LibreOffice $\AA$ Impress, juntamente com a ministrante do curso. Por fim, foi solicitado que os participantes elaborassem uma atividade de alfabetização utilizando o recurso tecnológico com o software LibreOffice $\AA$ Impress para o último encontro. Essa solicitação objetivou que os participantes tivessem a oportunidade de apresentar suas propostas, expondo facilidades, dificuldades e a forma com que desenvolveram as atividades. $O$ passo a passo foi encaminhado por e-mail, explicando de forma simplificada sobre como realizar a atividade no LibreOffice® Impress.

A partir do curso de capacitação de professores, as atividades de alfabetização utilizando materiais manipuláveis e o recurso tecnológico software LibreOffice $\mathbb{B}$ Impress foram apresentadas no terceiro e quarto encontros. As atividades têm como objetivo ensinar as vogais, iniciando da vogal " $A$ ", apresentando o som que ela representa e, assim, sucessivamente, ensinando as outras quatro vogais. Logo após a apresentação das vogais, deve-se iniciar a apresentação das sílabas (LEMLE, 2011), utilizando a correspondência alfabética de escrita biunívoca entre fonemas e letras e, por último, as palavras escritas com as figuras (GOMES, 2015).

As atividades adequam-se para alunos autistas a partir de 4 anos de idade e alunos autistas de nível leve que possuem ou não a linguagem, alunos que utilizam ou não recursos de Comunicação Alternativa (PECS) e para alunos que ainda não reconhecem as vogais. As atividades têm como objetivo apresentar as vogais e foram adaptadas e/ou elaboradas pela autora Guedes (2018) a partir dos autores Nico e Gonçalves (2016) e Fonseca e Ciola (2016).

De acordo com Nico e Gonçalves (2016), deve-se apresentar as quatro maneiras de escrita, sendo elas a cursiva minúscula e maiúscula, caixa alta e máquina. Porém, deve-se utilizar, posteriormente, das vogais caixa alta (GOMES, 2015), pois são de traçado simples e caracteres isolados. Foram utilizadas orientações teóricas do programa TEACCH para adaptações de atividades didáticas, do PECS, do método multissensorial com estímulo visual de Nico e Gonçalves (2016), e da abordagem de ensino, da autora Gomes (2015), iniciando pelas as vogais. As atividades devem ser realizadas individualmente, tendo o professor como orientador e mediador do processo. 
http://dx.doi.org/10.5902/1984686X41874

As figuras 2, 3 e 4 são atividades desenvolvidas no Curso de Capacitação, utilizando o recurso tecnológico o software Libreoffice® $\AA$.

Figura 2 - Apresentação da vogal "A" relacionando à figura.

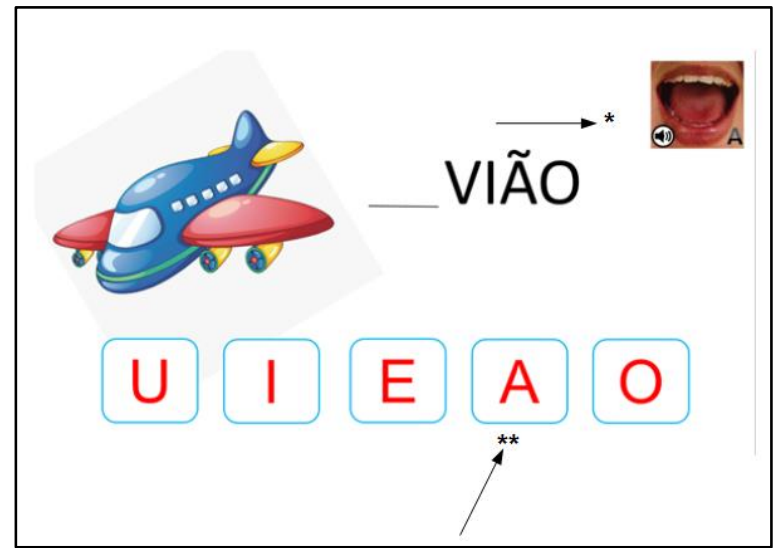

Fonte: Elaborada por Guedes (2018), a partir de Fonseca e Ciola (2016).

Figura 3 - Relacione a sílaba correspondente a figura.

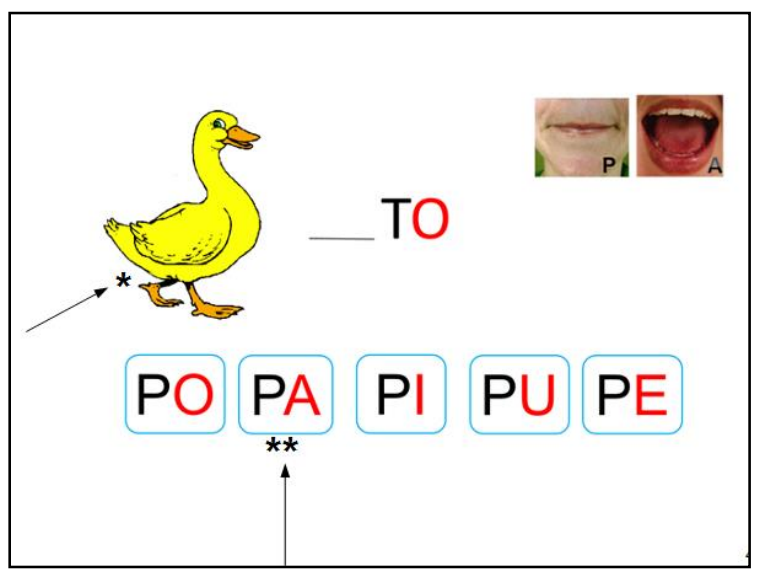

Fonte: Elaborada por Guedes (2018), a partir de Fonseca e Ciola (2016).

Figura 4 - Relacionar palavras com as figuras.

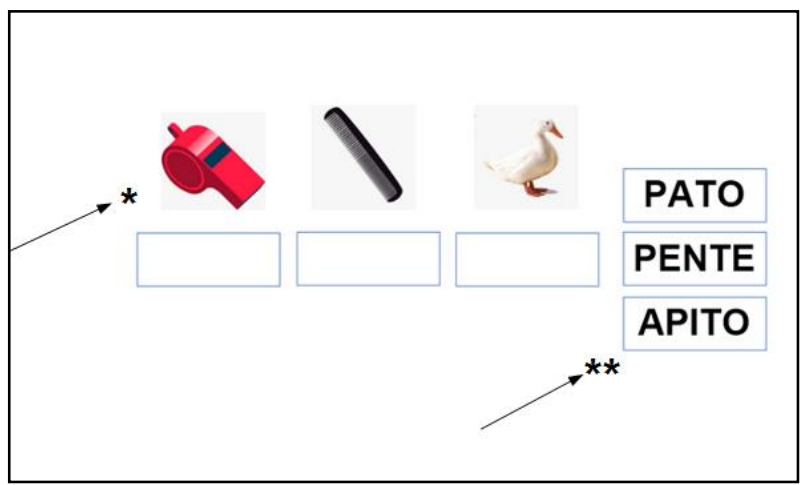

Fonte: Elaborada por Guedes (2018), a partir de Gomes (2015). 
http://dx.doi.org/10.5902/1984686X41874

\title{
Percepção das professoras quanto ao curso de capacitação
}

Os dados, coletados antes e durante o curso, representam as percepções dos participantes quanto aos métodos de alfabetização do TEA, sobre o recurso tecnológico, elencando suas dificuldades e facilidades, o material utilizado, com recursos tecnológicos, bem como sua compreensão e a avaliação do produto educacional, resultando pontos positivos e negativos.

A categoria elencada sobre o produto educacional da pesquisa, denominada Curso de capacitação, responsabiliza-se em analisar a Contribuição para prática em sala de aula, se houve a Aprendizagem do TEA, descrevendo as suas percepções quanto ao entendimento.

Do mesmo modo, aborda também as percepções dos professores participantes sobre as Atividades de Alfabetização do TEA, se atende a todos os alunos e, por fim, os Pontos Positivos quanto ao Curso de Capacitação proposto aos participantes, intitulado "Alfabetização de autistas com Recurso Tecnológico".

Com base nos resultados apresentados foi possível observar que $100 \%$ (10 participantes) descreveram que o Curso de Capacitação contribuiu para a sua prática em sala de aula com alunos autistas. Vale destacar o excerto do participante P4:

\begin{abstract}
o contato com os recursos midiáticos expostos pela mestranda trouxe para minha prática com o aluno Autista novas práticas com as tecnologias da informação e comunicação que promovem uma nova leitura na área educacional, e esta utilização adquada dos recursos midiáticos torna-se forte aliado no processo ensino e da aprendizagem do aluno com TEA. A mediação desse processo, deste curso que tive o privilégio de participar proporcionou uma nova perspectiva um novo olhar para um ensino mais rico e interessante para este aluno, para que caminhe a um resultado positivo de aprendizagem por meio de minha prática em sala de aula.
\end{abstract}

Passerino, Bez e Vicari (2013) abordam a importância do curso de capacitação do professor para o uso do recurso tecnológico, pois é um recurso que traz possibilidades de uma inclusão efetiva dos alunos com Autismo.

Destaca-se, no artigo 62, no $\S 1^{\circ}$, da LDB (BRASIL, 1996), que é responsabilidade da "União, o Distrito Federal, os Estados e Municípios, em regime de colaboração, deverão promover a formação inicial, a continuada e a capacitação dos profissionais de magistério".

Porém, os cursos de formação continuada realizados pelo Município ou Estado nem sempre vem ao encontro da necessidade de aprendizagem de cada professor; muitas vezes, faz-se necessário que o profissional busque outras alternativas de curso de interesse ou compatível com a realidade da sala de aula. 
http://dx.doi.org/10.5902/1984686X41874

Vale ressaltar a descrição do participante P6:

o curso de capacitação trouxe contribuições importantes para minha prática, visto que tenho um aluno Autista e tinha dúvidas de como trabalhar o conteúdo com ele. Aprender a desenvolver atividades utilizando a ferramenta LibreOffice ${ }^{\circledR}$ foi muito bom, visto que todos os professores possuem esse programa e não consegue utilizá-lo por falta de conhecimento.

Segundo Rodrigues, Lima e Vianna (2017), a formação inicial do professor não contempla todos os saberes necessários em face de todas as necessidades de uma sala de aula. Desse modo, é primordial que o profissional continue estudando e realizando, assim, a formação continuada, buscando aprimorar os seus conhecimentos e suas práticas.

Os participantes P3 e P9 descrevem que o curso de capacitação correspondeu tanto para atividades de alfabetização para alunos autistas quanto para o uso do recurso tecnológico de forma a atender todos os alunos, além disso para a sua formação docente. Vale ressaltar o excerto do participante P9:

com o curso aprendi como elaborar as atividades de alfabetização para meus alunos e como adaptar atividades de livros em sala regular. Com o recurso que aprendemos do LibreOffice ${ }^{\circledR}$, posso incluir todos meus alunos na mesma atividade.

Schneider, Franco e Slomp (2017) mencionam que o professor que conhece e desenvolve habilidades com software apresenta mais possibilidades, compartilhar novos conceitos e novas informações. O participante P1 relata que o uso do recurso tecnológico, no curso de capacitação, trouxe contribuições para a sua prática pedagógica em sala de aula, de forma a atender as necessidades dos alunos autistas.

Portanto, o professor necessita conhecer e aprender a manusear o software LibreOffice $\AA^{\circledR}$ para quebrar alguns paradigmas metodológicos para o uso do computador, de modo que sua utilização possa contribuir para o ensino e a aprendizagem de alunos com TEA. Como pode apontar o relato do P5, "conhecer práticas utilizando recursos midiáticos e suas aplicações contribuem para melhor aparelhamento e desenvolvimento de recursos destinados ao ensino".

Pimentel e Fernandes (2014) apresentam que os professores sentem necessidade de adquirir conhecimentos sobre as causas e características do TEA em sala de aula, pois enfrentam a falta de formação e apoio profissional.

Além da questão dos recursos tecnológicos, o curso também foi de fundamental importância para compreender mais sobre como ensinar e ajudar os participantes a observar mais seus alunos com Transtorno do Espectro Autista, obtendo compreensão nas 
http://dx.doi.org/10.5902/1984686X41874

teorias apresentadas sobre essa e os Recursos Tecnológicos, com foco no software LibreOffice $\AA$, bem como nas atividades práticas.

Portanto, foi possível concluir que, de acordo com os excertos dos participantes, o Curso de Capacitação promoveu momentos de reflexão, uma vez que levou o professor a articular conteúdos teóricos e práticos, tendo sido fundamentando no sentido de propiciar que o professor reflita sobre a sua própria prática.

Quanto ao Curso de Capacitação, identifica-se, nos excertos dos participantes, que 100\% (10 participantes) elogiaram as atividades que foram desenvolvidas, descrevendo que as aulas práticas facilitam a compreensão e preparam os profissionais para trabalhar com alunos com Transtorno do Espectro Autista. Nesse sentido, Marco, Spalato e Duarte (2013) abordam que as atividades devem ser simples e que devem ser realizadas de maneira direta, evitando, assim, o excesso de instruções verbais.

As atividades apresentadas, no curso de capacitação de professores, foram criativas e dinâmicas, com o intuito de promover o conhecimento dos participantes em relação às atividades para alunos autistas, auxiliando na busca de propostas de acordo com a necessidade de cada indivíduo. Vale destacar o excerto do P8:

as atividades de alfabetização desenvolvidas no curso para alunos autistas foram excelentes. A professora proporcionou outras atividades que podem ser adaptadas de acordo com cada aluno também mostrou livros e sites para pesquisas de atividades pedagógicas.

Ainda Silva (2015) informa que para ensinar alunos autistas, o professor é desafiado, pois esse processo exige que o profissional adapte recursos tradicionais de acordo com a necessidade e característica de cada aluno.

Para Alunos com Transtorno do Espectro Autista que apresentam dificuldades na coordenação motora, pode-se utilizar o computador como auxilio na alfabetização, pois a maioria possui habilidades no manuseio desses recursos (SANTOS; BISPO; PINHEIRO; SANTANA, 2013).

As atividades com o recurso tecnológico, apresentadas no Curso de Capacitação para Professores, são alternativas de ensino que proporcionam ao aluno Autista prazer em aprender, pois respeitam sua forma de compreender, além disso, podem ser utilizadas com outros alunos do atendimento educacional especializado e/ou desenvolvimento típico.

Sobre a utilização do recurso tecnológico para o ensino e aprendizagem de alunos autistas, 30\% dos participantes discorrem que atividades propostas no curso de capacitação de professores foram de extrema importância, possibilitando mais 
conhecimentos sobre essa ferramenta, visando despertar o interesse e aprimorar o ensino e potencializar aprendizagem dos alunos autistas. Tenório e Vasconcelos (2014) afirmam que o recurso tecnológico desperta motivação nos alunos, por ser algo atrativo tanto para alunos com TEA quanto para alunos com desenvolvimento típico. Ramos (2009) aborda que a tecnologia oferece possibilidades de interação, tornando a aula mais interativa, como vale ressaltar a descrição do P5, "a perpectiva adotada nessas atividades se mostra interessante e aplicável, devido as atividades encorajarem a interação do aluno e por sua elaboração não precisar de um especialista em tecnologia de informática".

O recurso tecnológico no ambiente escolar tem a sua importância, pois amplia a aquisição de conhecimentos dos alunos (OTTO, 2016). Assim, as atividades desenvolvidas, tanto manuais quanto com o recurso tecnológico, contribuíram para aprendizagem das participantes, pois foram utilizados diversos recursos e métodos para a elaboraração das atividades, como relata o $\mathrm{P9}$ :

achei interessante o quanto podemos e devemos diversificar a maneira de apresentar a mesma coisa ao aluno. Com as atividades, aprendemos adaptála atividades com uso de Pecs, trabalho auditivo e também o trabalho com recursos midiáticos.

Desse modo, o professor pode conduzir os alunos autistas para o conhecimento, proporcionando novas descobertas por meio de recursos diferenciados, atrativos, como os recursos tecnológicos e/ou manipuláveis, viabilizando conteúdos como de alfabetização e facilitando a aprendizagem dos alunos com TEA.

No curso realizado, foram trabalhadas as definições, causas e características de alunos com Transtorno do Espectro Autista, para que os participantes alcançassem o conhecimento referente ao tema abordado. Com base nos excertos dos participantes, nos dados coletados por meio da entrevista, identifica-se que os participantes obtiveram a compreensão e o entendimento sobre o Transtorno do Espectro Autista. O TEA é caracterizado por comprometimentos nas interações sociais, desvios na comunicação e comportamentos restritos e esterotipados (KOVATLI, 2003). Dentro das definições sobre o Espectro e as características do TEA, vale destacar o que o P4 descreve:

a professora expôs de forma clara de como ensinar o TEA que pode ser classificado em Grau leve, Grau Moderado, Grau Severo, o apoio necessário para contemplar as necessidades de cada um, considerando as dificuldades na comunicação, nos interesses restritos e comportamentos apresentados. 
http://dx.doi.org/10.5902/1984686X41874

Segundo Gadia e Rotta (2016), crianças com TEA de nível leve são bastantes funcionais e necessitam de pouca intervenção; as de nível moderado são crianças relativamente funcionais, sendo necessária muita intervenção, e, por fim, no nível severo, são crianças pouquíssimo funcionais, apresentando dificuldades mesmo com muita intervenção.

Além de compreender e entender os comportamentos do aluno com Transtorno do Espectro Autista, faz-se necessário que o professor, do mesmo modo, entenda como trabalhar conteúdos escolares. Dessa forma, o P6 descreve que houve compreensão em relação aos comportamentos e sobre a aprendizagem dos alunos com TEA, mas o entendimento maior foi, principalmente, na elaboração das atividades para alfabetização por meio do recurso tecnológico.

Tenório e Vasconcelos (2014) reforçam que os recursos tecnológicos são instrumentos que podem ser eficazes no desenvolvimento de alunos autistas, sendo uma forma de facilitar o processo de ensino e aprendizagem.

Assim, faz-se imprescindível que o professor estabeleça estratégias pedagógicas que possibilitem o desenvolvimento integral do aluno com TEA (FERNANDES; SILVA, 2016).

Vale ressaltar que, durante o curso de capacitação dos professores, surgiu a unidade emergente em relação à implementação das atividades propostas de alfabetização utilizando o recurso tecnológico.

A partir das descrições, observou-se que $40 \%$ dos participantes implementaram as atividades com seus alunos com atendimento educacional especializado.

Kovatli (2003) aborda que os softwares utilizados como recursos educacionais digitais apresentam objetivos para serem compreendidos, buscando trabalhar de acordo com a necessidade de cada educando, contribuindo para apropriação de conteúdo e com a função de alcançar a aprendizagem.

O P4 relatou que utilizou o recurso tecnológico com o software LibreOffice®:

foi proposto ao aluno (em processo de avaliação) o recurso midiático na conjugação de verbo. Por estar em um quinto ano, preparei uma atividade em que pudesse conjugar o verbo no presente, pretérito perfeito e pretérito imperfeito em que o final da palavra muda conjugação em colorido. Aplicado somente o presente por enquanto! No notebook da professora enquanto os outros alunos executavam a tarefa escrevendo. $O$ aluno gostou chamou atenção para realização da tarefa. Terá continuidade aos demais tempos verbais. 
http://dx.doi.org/10.5902/1984686X41874

Segundo Spalato e Duarte (2013), ao ensinar, o conteúdo deve ser organizado em pequenos passos de maneira mais direta; as atividades têm que diminuir as dificuldades do aluno.

É importante ressaltar que os pontos positivos sobressaíram-se aos pontos negativos; apenas $20 \%$ (2 participantes) descreveram sobre a carga horária que foi pouca e a necessidade de mais encontros presenciais devido ao assunto ser abrangente. A base desse curso foi "Alfabetização de Alunos autistas com Recurso Tecnológico", totalizando em uma carga horária de 40 horas.

O curso de capacitação buscou a relação entre a teoria e a prática, de forma que trouxesse reflexão e que pudessem ser pensadas, em diferentes perspectivas, as características do TEA. Os participantes P5 e P10 disseram que o curso foi bem estruturado, colocando a teoria na prática.

Araújo e Reis (2014) abordam que

formação continuada é o momento do professor aprender novos conceitos, discussões atuais referentes à educação e, principalmente, refletir sobre a sua ação docente, (re)significar sua postura profissional, no sentido de aprimorá-la, ou sustentar práticas já existentes. (ARAÚJO; REIS, 2014, p. 5).

Portanto, a formação pode auxiliar os profissionais na sua prática, trazendo novas metodologias, conhecimentos, recursos e teorias que podem direcionar o trabalho com os alunos, melhorando a sua prática em sala de aula.

\section{Considerações finais}

Evidencia-se a importância do uso do recurso tecnológico para o ensino, porém, é visível a escassez de propostas de ensino de conteúdos acadêmicos, como a alfabetização de alunos com TEA, assim como propostas de formação continuada para professores com o intuito de ensiná-los a manusear essa ferramenta como apoio pedagógico.

Diante das análises, os resultados da pesquisa revelaram uma percepção positiva quanto ao curso de capacitação de professores utilizando o recurso tecnológico notebook, com o software LibreOffice $\mathbb{B}$ Impress. Sua execução mostrou-se aplicável e as atividades com o auxílio do instrumento foram consideradas facilitadoras para aprendizagem dos alunos com Transtorno do Espectro Autista e, principalmente, para o ensino público, pois o curso teve como princípio o uso de materiais e/ou instrumentos gratuitos, que podem ser utilizados, principalmente, nas escolas públicas brasileiras. 
http://dx.doi.org/10.5902/1984686X41874

\section{Referências}

AMERICAN PSYCHIATRIC ASSOCIATION. DSM-V. Manual Diagnóstico e Estatístico de Transtornos Mentais. ed. 5ํ, 2014.

ARAÚJO, Roberta Negrão de; REIS, Sandra Regina dos. A formação continuada e sua contribuição para o professor alfabetizador. In: ANPED SUL, 10., 2014,

Florianópolis. Congresso. Florianópolis, 2014. p. 1 - 20.

BOGDAN, Robert BIKLEN, Sari Knopp. Investigação Qualitativa em Educação: uma introdução à teoria e aos métodos. Porto/Portugal: Porto Editora, 1994.

BORDINI, Daniela; BRUNI, Ana Rita. Transtornos do Espectro autista. In: ESTANISLAU, Gustavo M.; BRESSAN, Rodrigues Affonseca. Saúde Mental na Escola: o que os educadores devem saber. 1. ed. Porto Alegre: Artmed, 2014. p. 219-230.

BRASIL. Ministério de Educação. LDB - Lei no 9394/96, de 20 de dezembro de 1996. Estabelece as diretrizes e bases da Educação Nacional. Brasília: MEC, 1996.

BRASIL. Ministério da Educação. Secretaria da Educação Fundamental. Parâmetros Curriculares Nacionais. Brasília: MEC/SEF, 1998.

FERNANDES, Adriano Hidalgo; SILVA, Rosane Gumiero Dias da. Formação do professor para a inclusão do aluno com transtorno do espectro Autista (TEA) na rede regular de ensino. 2016. 18 f. TCC (Graduação) UEM, 2016.

FLICK, Uwe. Introdução à pesquisa qualitativa. 3 ed. Porto Alegre: Artmed, 2009.

FONSECA, Maria Elisa Granchi; CIOLA, Juliana de Cássia Baptistella. Vejo e Aprendo: Fundamentos do Programa TEACCH. 2. ed. Ribeirão Preto: Book Yoy, 2016.

GADIA, Carlos; ROTTA, Newra Tellechea. Aspectos Clínicos do Transtorno do Espectro Autista. In: ROTTA, Newra Tellechea; OHLWEILER, Lygia; RIESGO, Rudimar dos Santos. Transtorno de Aprendizagem. 2. ed. Porto Alegre: Artmed, 2016. p. 368-377.

GOMES, Camila Graciella Santos; Ensino de leitura para pessoas com autismo. 1 ed. Curitiba: Appris, 2015.

GOULART, Jéssica Cristina; BLANCO, Marília Bazan; COELHO NETO, João. O Jogo Digital em Tecnologia Touch como Instrumento de Aprendizagem para Criança autista. ESPACIOS (CARACAS), v. 38, p. 15-23, 2017.

GOMES, Camila Graciella Santos; SILVEIRA, Analice Dutra. Ensino de habilidades básicas para pessoas com autismo. 1 ed. Curitiba: Appris, 2016.

GUEDES, Danieli Ferreira. 0 uso das tecnologias digitais para a alfabetização de alunos com transtorno do espectro autista: proposta de um curso de capacitação. 2018. 190 f. Dissertação (Mestrado em Ensino) Universidade Estadual Norte do ParanáCampus Cornélio Procópio, 2018. 
http://dx.doi.org/10.5902/1984686X41874

KOVATLI, Marieli de Fátima. Estratégias para estabelecer a interação da criança com autismo e o computador. 2003. 114 f. Dissertação (Mestrado em Ciência da Computação). Universidade Federal de Santa Catarina, Florianópolis, 2003.

LEMLE, Miriam. Guia Teórico do Alfabetizador. São Paulo: Ática, 2011.

MAGALHÃES, Mônica Giacomassi Menezes de. Metodologia para integração de novas tecnologias na formação de professores. 2004. 170 f. Tese (Doutorado), Universidade de São Paulo, São Carlos, 2004.

MARCO, Carmem Lydia da Silvia Trunci de; SPALATO, Marina Helena Trunci Oliveira; ROSALIEDUARTE, Viviane. Estratégias Acadêmicas. In: BRUNI, Ana Rrita; GADIA, Carlos; MARCO, Carmem Lydia da Silvia Trunci de. Autismo e Realidade. São Paulo, 2013. p. 1-84.

MORAES, Roque. Uma tempestade de luz: a compreensão possibilitada pela análise textual discursiva. Ciência \& Educação, v.9, n. 2, p.191-211, 2003.

MORAES, Roque; GALIAZZI, Maria Carmo do. Análise Textual Discursiva. $2^{\underline{a}}$ ed. ver. ljuí: Editora UNIJUÍ: 2014.

NICO, Maria Ângela Nogueira; GONÇALVES, Áurea Maria Stavale. Facilitando a Alfabetização Multissensorial, Fônica e Articulatória. 2 ed. Ribeirão Preto: Book Toy, 2016.

NÓVOA, Antônio. Formação de professores e profissão docente. In: NÓVOA, António (Coord.) Os professores e sua formação. Lisboa: Dom Quixote, 1995.

NUNES, Débora Regina de Paula; SANTOS, Larissa Bezerra dos. Mesclando práticas em Comunicação Alternativa: caso de uma criança com autismo. Revista Quadrimestral da Associação Brasileira de Psicologia Escolar e Educacional, São Paulo, v. 19, n. 1, p. 59-69, abr. 2015.

NUNES, Débora Regina de Paula; AZEVEDO, Maria Queiroz Orrico; SCHMIDT, Carlo Inclusão educacional de pessoas com autismo no Brasil: uma revisão da literatura. Revista Educação Especial, v. 26, n. 47, p. 557-572, set-dez. 2013.

OTTO, Patrícia Aparecida. A importância do uso das tecnologias nas salas de aula nas series iniciais do ensino fundamental 1. 2016. Universidade Federal de Santa Catarina, Florianópolis, 2016. p.1-18.

PASSERINO, Liliana Maria; BEZ, Maria Rosangela; VICARI, Rosa Maria. Formação de professores em comunicação alternativa para crianças com TEA: contextos em Ação.

Revista de Educação Especial, Santa Maria, v.26, n.47, p. 619 - 638, dezembro 2013.

PIMENTEL, Ana Gabriela Lopes; FERNANDES, Fernanda Dreux Miranda. A perspectiva de professores quanto ao trabalho com crianças com autismo. Audiology - Communication Research, [S.I.], v. 19, n. 2, p.171-178, abr. 2014. 
http://dx.doi.org/10.5902/1984686X41874

RAMOS, Daniela Karine. A formação de professores para o uso das tecnologias: um mosaico de concepções e emoções. Renote: Novas Tecnologias na Educação, v. 7, n. 1, p.1-11, jul. 2009.

RODRIGUES, Polyana Marques Lima. LIMA, Willams dos Santos Rodrigues; VIANA, Maria Aparecida Pereira. A Importância da Formação Continuada de Professores da Educação Básica: A Arte de Ensinar e o Fazer Cotidiano. Saberes Docentes em Ação, S[I], v. 3, n. 1, p.28-48, set. 2017.

SANTOS, Adriano dos; et al. Metodologias de ensino para crianças autistas: superando limitações em busca da inclusão. Anais Fiped V (2013), Edição № 2, Vol. 1.

SCHNEIDER, Daniele da Rocha; FRANCO, Sérgio Roberto Kieling; SLOMP, Paulo Francisco. Software livre na educação: uma experiência em cursos de formação docente. Texto Livre Linguagem e Tecnologia, Belo Horizonte, v. 9, n. 2, p.199-218, dez. 2016.

SEGGER, Vania; CANES, Suzy Elizabeth; GARCIA, Carlos Alberto Xavier. Estratégias Tecnológicas na Prática Pedagógica. Monografias Ambientais, Cascavel, v. 8, n. 8, p.18871899, ago. 2012.

SILVA, Ana Maria; OLIVEIRA, Marta Regina Furlan de. A relevância da formação continuada do (a) professor (a) de educação infantil para uma prática reflexiva. In: Seminário de Pesquisa de CEMAD, 2., 2014, Londrina. Anais... Londrina: UEL, 2014. p. 69-81.

SILVA, Edna Lúcia da; MENEZES, Estera Muszkat. Metodologia da Pesquisa e Elaboração de Dissertação. 2005. 139 f. Dissertação (Mestrado em Informática) Universidade Federal de Santa Catarina, Florianópolis, 2005.

SILVA, Isailde Alves Santos. Papel do Professor Frente aos Desafios da Inclusão de Aluno autista. 2015. 32 f. (Especialização Inclusão). Universidade de Brasília, Brasília, 2015.

SOUSA, Maria Josiane Sousa de. Professor e o autismo: desafios de uma inclusão com qualidade. 2015. 34 f. (Especialização Educação Especial). Universidade de Brasília, Brasília, 2015.

TENÓRIO, Mylena Carla Almeida; VASCONCELOS, Norma Abreu Lima Maciel. Autismo: a tecnologia como ferramenta assistiva ao processo de ensino e aprendizagem de uma criança dentro do espectro. In: Congresso Internacional de Educação e Inclusão, 2014, Campina Grande. Anais... Campina Grande, 2014. p. 1 - 9.

TOGASHI, Cláudia Miharu; WALTER, Cátia Crivelenti de Figueiredo. As Contribuições do Uso da Comunicação Alternativa no Processo de Inclusão Escolar de um Aluno com Transtorno do Espectro do Autismo. Revista Brasileira de Educação Especial, Marília, v. 22, n. 3, p. 351-366, set. 2016.

ZANIN, Chirley Travaglia; BLANCO, Marília Bazan. Inclusão digital: informática educativa na sala de recursos. 2009. 30 f. (Especialização Educação Especial). Universidade Estadual Norte do Paraná, Cornélio Procópio, 2009. 
http://dx.doi.org/10.5902/1984686X41874

\section{Notas}

1 Um termo utilizado referente ao DSM-IV, atualmente utiliza-se o termo Transtorno do Espectro Autista de acordo com o DSM-V.

2 Esse termo possui várias nomenclaturas como: as Tecnologias da Informação e Comunicação (TICS), as Tecnologias Digitais; Recursos Midiáticos e Recursos Tecnológicos, porém optou-se por abordar nessa pesquisa o Recurso Tecnológico.

${ }^{3}$ Impress é um programa contido na suíte de aplicativos LibreOffice ${ }^{\circledR}$ e pode ser utilizado para criar apresentações em slide

${ }^{4}$ É um aplicativo para facilitar a leitura e escrita do aluno Autista, formando palavra simples.

${ }^{5}$ Atividade da vida diária.

${ }^{6}$ É dividido em 4 níveis: o $1^{\circ}$ aprende a transposição de imagens; $2^{\circ}$ habilidades concretas e discriminação, como: maior/menor, forma geométrica e cores; $3^{\circ}$ exige maior raciocínio e $4^{0}$ aborda letramento repartição de sílabas, vogais e palavras.

${ }^{7}$ Sistema de Comunicação Alternativa para Letramento de Pessoas.

\section{Correspondência}

Danieli Ferreira Guedes - Escola Municipal Eunice Gatti Gomes, Rua Pres. Washington Luís, 305, Cornélio Procópio, Paraná - Brasil

CEP: $86300-000$

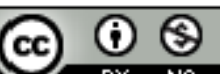

EY Th 4.0 International (CC BY-NC 4.0) 